\title{
Pengaruh Penunasan dan Pemberian Pupuk NPK Phonska Terhadap Produksi Tanaman Kelapa Sawit (Elaeis guineensis jacq)
}

\section{Penunasan Influence and Administration of NPK Fertilizer Production Plant Phonska Against Palm Oil (Elaeis guineensis jacq)}

\author{
Haminin $^{1}$, Tutik Nugrahini ${ }^{2}$ dan Purwati $^{2}$ \\ 1Alumni Program Studi Agroteknologi, Fakultas Pertanian, Universitas Widya Gama Mahakam \\ Jl. KH. Wahid Hasyim, Sempaja, Samarinda, Kalimantan Timur, Indonesia. \\ ${ }^{2}$ Tenaga Pendidik Program Studi Agroteknologi, Fakultas Pertanian, Universitas Widya Gama Mahakam \\ Jl. KH. Wahid Hasyim, Sempaja, Samarinda, Kalimantan Timur, Indonesia. \\ email : hminin@gmail.com, tutik_nugrahini@yahoo.com,purwatibaik@yahoo.co.id
}

Diterima : 12 Juni 2012 Disetujui : 5 September 2012

\section{ABSTRACT}

\begin{abstract}
Penunasan influence and NPK fertilizer production plant Phonska against oil palm (Elaeis guineensis jacq). The aim of research to determine the effect penunasan, Phoska NPK fertilizer and its interaction with the production of oil palm plantations. Research carried out for 4 months, starting from May to August 2010. The location of the research in the Garden State Agricultural Polytechnic Pilot Samarinda. Research arranged in a randomized block design (RAK) with $2 \times 4$ factorial experiment 3 times the number of replicates. The treatment consists of two factors: The first factor is Penunasan $(P)$ which comprises, namely: $p 0=$ without penunasan, $p 1=$ with penunasan. The second factor is Phonska $N P K$ fertilizer which consist of 4 levels, namely: $m 0=0 \mathrm{~kg} /$ plant, $\mathrm{ml}=0.5 \mathrm{~kg} /$ staple crops, $\mathrm{m} 2=1.0 \mathrm{~kg} / \mathrm{plant}$, $\mathrm{m} 3$ $=1.5 \mathrm{~kg} /$ plant. The results showed the treatment penunasan very significant effect on the weight and number of TBS TBS. Penunasan best treatment on $\mathrm{pl}$ (with penunasan). , NPK fertilizer treatment Phonska very significant effect on the increase in production of oil palm plantations. There is interaction between treatment penunasan with NPK fertilizer production peningkataan Phonska against oil palm plantations.
\end{abstract}

Keywords: penunasan, NPK Phonska and palm oil

\section{PENDAHULUAN}

Kelapa Sawit di Indonesia dewasa ini merupakan komoditas primadona, luasnya terus berkembang dan tidak hanya monopoli perusahaan besar negara atau perkebunan besar swasta tetapi juga oleh petani. Perkebunan kelapa sawit yang semula di Sumatera Utara dan Daerah Istimewa Aceh saat ini sudah berkembang di beberapa provinsi termasuk Kalimantan Timur. Jumlah perkebunan Besar Swasta (PBS) yang aktif di Kalimantan Timur sampai posisi bulan Desember 2004 sebanyak 145 PBS dengan luas areal / izin lokasi dari Bupati / Walikota seluas 1.801.123.73 ha. Peningkatan luas areal perkebunan kelapa sawit tersebut diharapkan juga mempunyai produksi yang baik. Upaya untuk meningkatkan produksi dapat dilakukan dengan perbaikan teknik budidaya kelapa sawit antara lain yang dapat dilakukan adalah teknik penunasan dan pemupukan tanaman kelapa sawit.

Penunasan berarti membuang atau memangkas daun yang berada di bawah buah. Penunasan dilakukan dengan tujuan sebagai berikut : membersihkan tanaman supaya pollen mudah

\section{BAHAN DAN METODE}

Penelitian ini dilaksanakan selama empat bulan, terhitung mulai bulan Mei sampai dengan Agustus 2010. Lokasi penelitian di Kebun 49 membuahi putik (bunga betina), memudahkan pekerjaan untuk mengambil atau memotong buah yang sudah masak dan secara fisiologis, daundaun yang sudah tua di bagian bawah tidak efektif lagi untuk melakukan fotosintesis. Agar tanaman dapat dengan baik dan menghasilkan produksi yang tinggi, diperlukan unsur hara atau makanan yang cukup. Untuk hara utama yang dibutuhkan tanaman adalah Nitrogen $(\mathrm{N})$, Fosfor $(\mathrm{P})$, dan Kalium (K). Tidak dipenuhinya salah satu unsur hara tersebut akan mengakibatkan menurunnya kualitas dan kuantitas hasil produksi pertanian. Unsur hara N, P, K di dalam tanah tidak cukup tersedia dan terus berkurang karena diambil untuk pertumbuhan tanaman dan terangkut pada waktu panen, tercuci, menguap dan erosi. Untuk mencukupi kekurangan unsur hara $\mathrm{N}, \mathrm{P}$ dan $\mathrm{K}$ pada tanaman kelapa sawit maka perlu dilakukan pemupukan. Pupuk NPK yang dapat digunakan antara lain NPK Phonska.

Berdasarkan uraian tersebut, maka perlu adanya penelitian mengenai teknik budidaya khususnya penunasan dan pemupukan NPK Phonska terhadap produksi tanaman kelapa sawit (Elaeis guneensis Jacq ).

Percontohan Politeknik Pertanian Negeri Samarinda. Bahan yang digunakan ; tanaman kelapa sawit umur delapan tahun, pupuk majemuk NPK Phonska. Alat yang digunakan ; Alat-alat 
tulis, timbangan, kamera, cangkul, dodos, parang, gancu, tojok, arit, chisel, kantung plastik. Penelitian mengggunakan Rancangan Acak Kelompok (RAK) dengan percobaan faktorial $2 \mathrm{x}$ 4 jumlah ulangan sebanyak 3 kali. Perlakuan terdiri dari 2 faktor, yaitu : Faktor pertama adalah Penunasan / pemangkasan pelepah (P) yang terdiri, yaitu : $\mathrm{p}_{0}=$ tanpa penunasan $/$ pemangkasan pelepah, $\mathrm{p}_{1}=$ dengan penunasan $/$ pemangkasan pelepah. Faktor kedua adalah pemberian pupuk NPK Phonska yang terdiri dari 4 taraf, yaitu : $\mathrm{m}_{0}=0 \mathrm{~kg} / \mathrm{tanaman}, \mathrm{m}_{1}=0,5 \mathrm{~kg} /$ pokok tanaman, $\mathrm{m}_{2}=1,0 \mathrm{~kg} / \mathrm{tanaman}, \mathrm{m}_{3}=1,5$

\section{HASIL DAN PEMBAHASAN}

\section{Pengaruh Perlakuan Penunasan}

\section{Berat tandan buah segar}

Tabel 1. Rata-Rata Berat TBS pada Perlakuan Penunasan

\begin{tabular}{ccccc}
\hline Perlakuan & \multicolumn{4}{c}{ Berat TBS $(\mathrm{kg})$} \\
\cline { 2 - 5 } Penunasan & Mei & Juni & Juli & Agustus \\
\hline $\mathrm{p}_{0}$ & $10,17^{\mathrm{b}}$ & $12,67^{\mathrm{b}}$ & $14,83^{\mathrm{b}}$ & $14,67^{\mathrm{b}}$ \\
$\mathrm{p}_{1}$ & $30,08^{\mathrm{a}}$ & $32,08^{\mathrm{a}}$ & $44,67^{\mathrm{a}}$ & $32,58^{\mathrm{a}}$ \\
\hline
\end{tabular}

Keterangan : Angka-angka yang diikuti huruf yang sama menunjukkan tidak berbeda nyata berdasarkan uji BNT pada taraf $\alpha=5 \%$

Hasil sidik ragam menunjukan bahwa perlakuan penunasan berpengaruh sangat nyata terhadap berat tandan buah segar kelapa sawit. Hasil uji BNT 5\% menunjukkan bahwa perlakuan penunasan $\mathrm{p}_{1}$ (dengan penunasan) untuk parameter berat tandan buah segar berbeda nyata dengan $\mathrm{p}_{0}$ (tanpa penunasan). Rata-rata berat tandan buah segar terberat dicapai pada perlakuan $\mathrm{p}_{1}$ berturut turut adalah 30,08 $\mathrm{kg}$ (panen pertama), 32,08 $\mathrm{kg}$ (panen kedua), 44,67 kg (panen ketiga) dan 32,58 $\mathrm{kg}$ (panen keempat) sedangkan rata-rata berat tandan buah segar teringan dicapai pada perlakuan $\mathrm{p}_{0}$ berturut - turut adalah 10,17 $\mathrm{kg}$ (panen pertama), 12,67 $\mathrm{kg}$ (panen kedua), 14,83 kg (panen ketiga) dan $14,57 \mathrm{~kg}$ (panen keempat). Hal ini diduga karena perlakuan penunasan $\mathrm{p}_{1}$ akan membentuk ukuran tandan yang semakin besar karena cukup ruang untuk perkembangan buah. Penunasan songgo dua dengan menyisakan dua pelepah yang sejajar di bawah tandan buah $\mathrm{kg} /$ tanaman. Pelaksanaan penelitian meliputi ; persiapan alat dan bahan, penunasan, pemberian pupuk NPK Phonska, pengendalian gulma dan pemanenan. Pengambilan data meliputi ; jumlah tandan buah segar, berat tandan buah segar dan produksi buah kelapa sawit. Untuk menguji pengaruh perlakuan digunakan Sidik Ragam. Jika hasil sidik ragam diperoleh hasil yang berpengaruh nyata atau berpengaruh sangat nyata maka dilakukan uji lanjut BNT pada taraf 5\% yang berguna untuk membandingkan rata-rata perlakuan yang satu dengan yang lainnya.

\section{Jumlah tandan buah segar}

Tabel 2. Rata-Rata Jumlah TBS pada Perlakuan Penunasan

\begin{tabular}{ccccc}
\hline Perlakuan & \multicolumn{4}{c}{ Jumlah TBS pada bulan } \\
\cline { 2 - 5 } Penunasan & Mei & Juni & Juli & Agustus \\
\hline $\mathrm{p}_{0}$ & $1,00^{\mathrm{b}}$ & $1,00^{\mathrm{b}}$ & $1,00^{\mathrm{b}}$ & $1,00^{\mathrm{b}}$ \\
$\mathrm{p}_{1}$ & $1,67^{\mathrm{a}}$ & $1,42^{\mathrm{a}}$ & $2,08^{\mathrm{a}}$ & $1,25^{\mathrm{a}}$ \\
\hline
\end{tabular}

Keterangan : Angka-angka yang diikuti huruf yang sama menunjukkan tidak berbeda nyata berdasarkan

Keterangan : Angka-angka yang diikuti huruf yang sama menunjukkan tidak berbeda nyata berdasarkan
uji BNT pada taraf $\alpha=5 \%$

\begin{abstract}
yang paling tua membuat tandan buah tidak terlalu tertekan pelepah yang dapat menghambat perkembangan buah karena pelepah akan membuka ke samping sehingga membuat ruang yang cukup untuk perkembangan buah menjadi lebih besar. Selain itu dengan penunasan songgo dua memberikan kemudahan dalam hal penyerbukan sehingga semakin banyak terjadi penyerbukan yang membuat buah semakin banyak dalam tiap tandannya. Hal ini sesuai dengan pendapat Sastrosayono (2003) yang menyatakan bahwa penunasan berarti membuang atau memangkas daun yang berada di bawah buah. Penunasan dilakukan dengan tujuan membersihkan tanaman supaya pollen mudah membuahi putik (bunga betina). Berdasarkan uraian tersebut dapat diketahui bahwa dengan penunasan berpengaruh terhadap berat tandan buah segar yang dihasilkan tanaman kelapa sawit.
\end{abstract}


Hasil sidik ragam menunjukan bahwa perlakuan penunasan berpengaruh sangat nyata pada tiga panen kelapa sawit dan berpengaruh nyata pada panen keempat kelapa sawit terhadap jumlah tandan buah segar kelapa sawit. Hasil uji BNT 5\% menunjukkan bahwa perlakuan penunasan $\mathrm{p}_{1}$ (dengan penunasan) untuk parameter jumlah tandan buah segar berbeda nyata dengan $\mathrm{p}_{0}$ (tanpa penunasan). Rata-rata jumlah tandan buah segar terbanyak dicapai pada perlakuan $\mathrm{p}_{1}$ berturut - turut adalah 1,67 TBS (panen pertama), 1,42 TBS (panen kedua), 2,08 TBS (panen ketiga) dan 1,25 TBS (panen keempat) sedangkan ratarata jumlah tandan buah segar paling sedikit dicapai pada perlakuan $\mathrm{p}_{0}$ berturut - turut adalah 1,00 TBS (panen pertama), 1,00 TBS (panen kedua), 1,00 TBS (panen ketiga) dan 1,00 TBS (panen keempat). Hal ini diduga karena perlakuan penunasan $\mathrm{p}_{1}$ dengan metode penunasan songgo dua dengan menyisakan dua pelepah yang sejajar di bawah tandan buah yang paling tua membuat ruang yang cukup lebar karena jumlah pelepah yang tidak terlalu padat sehingga memudahkan dalam penyerbukan untuk membentuk buah. Hal ini sesuai dengan tujuan penunasan menurut Sastrosayono (2003) yaitu membersihkan tanaman supaya pollen mudah membuahi putik (bunga betina). Oleh karena itu, semakin banyak bunga betina yang dibuahi bunga jantan akan menghasilkan tandan buah segar yang semakin banyak pula.

\section{Pengaruh Perlakuan Pemberian Pupuk NPK Phonska}

\section{Berat tandan buah segar}

Tabel 3. Rata-Rata Berat TBS pada Perlakuan Pupuk NPK Phonska

\begin{tabular}{ccccc}
\hline Pupuk NPK & \multicolumn{4}{c}{ Berat TBS $(\mathrm{kg})$} \\
\cline { 2 - 5 } Phonska & Mei & Juni & Juli & Agustus \\
\hline $\mathrm{m}_{0}$ & $11,83^{\mathrm{c}}$ & $13,50^{\mathrm{c}}$ & $19,17^{\mathrm{c}}$ & $17,33^{\mathrm{c}}$ \\
$\mathrm{m}_{1}$ & $14,17^{\mathrm{c}}$ & $17,00^{\mathrm{c}}$ & $27,83^{\mathrm{b}}$ & $20,00^{\mathrm{bc}}$ \\
$\mathrm{m}_{2}$ & $29,67^{\mathrm{a}}$ & $33,17^{\mathrm{a}}$ & $39,83^{\mathrm{a}}$ & $30,83^{\mathrm{a}}$ \\
$\mathrm{m}_{4}$ & $24,83^{\mathrm{b}}$ & $25,83^{\mathrm{b}}$ & $32,17^{\mathrm{b}}$ & $26,33^{\mathrm{ab}}$ \\
\hline
\end{tabular}

Keterangan : Angka-angka yang diikuti huruf yang sama menunjukkan tidak berbeda nyata berdasarkan uji BNT pada taraf $\alpha=5 \%$

Hasil sidik ragam menunjukan bahwa perlakuan pemberian pupuk NPK Phonska berpengaruh sangat nyata terhadap berat tandan buah segar kelapa sawit. Hasil uji BNT 5\% menunjukkan bahwa rata-rata berat tandan buah segar terberat dicapai pada perlakuan $\mathrm{m}_{2}(1,0 \mathrm{~kg} /$ pokok tanaman) berturut -turut adalah $29,67 \mathrm{~kg}$ (panen pertama), 33,17 kg (panen kedua), 39,83 $\mathrm{kg}$ (panen ketiga) dan 30,83 $\mathrm{kg}$ (panen keempat) sedangkan rata-rata berat tandan buah segar teringan dicapai pada perlakuan $\mathrm{m}_{0}$ (tanpa perlakuan) berturut - turut adalah 11,83 kg (panen pertama), 13,50 kg (panen kedua), 19,17 kg (panen ketiga) dan $17,33 \mathrm{~kg}$ (panen keempat). Hal ini diduga karena perlakuan $\mathrm{M}_{2}$ telah mampu memenuhi kebutuhan unsur hara tanaman untuk pertumbuhan dan perkembangan tanaman terutama buah. Hasil analisis tanah pada Lampiran 10 menunjukkan bahwa kandungan unsur N, P, K tergolong sangat rendah berdasarkan status kesuburan tanah menurut Hardjowigeno (1992). Dengan perlakuan $\mathrm{m}_{2}$ maka ketersediaan unsur hara $\mathrm{N}, \mathrm{P}$ dan $\mathrm{K}$ yang dapat diserap tanaman diduga meningkat dan tersedia dalam jumlah cukup dan seimbang sehingga mempengaruhi produksi kelapa sawit yang ditunjukkan pada parameter berat tandan buah segar kelapa sawit. Menurut Sarief (1986), kesuburan tanah merupakan faktor terpenting untuk menghasilkan produksi pertanian yang optimal tanpa mengurangi tingkat kesuburan tanahnya. Ketersedian unsur hara yang dapat diserap oleh tanaman merupakan faktor untuk mempengaruhi tingkat produksi tanaman. Kemudian diperjelas oleh Petrokimia (2005) yang menyatakan bahwa agar tanaman dapat tumbuh dengan baik dan menghasilkan produksi yang tinggi, diperlukan unsur hara atau makanan yang cukup. Untuk hara utama yang dibutuhkan tanaman adalah Nitrogen $(\mathrm{N})$, Fosfor (P), dan Kalium (K). Tidak dipenuhinya salah satu unsur hara tersebut akan mengakibatkan menurunnya kwalitas dan kuantitas hasil produksi pertanian. Unsur hara N, $\mathrm{P}, \mathrm{K}$ di dalam tanah tidak cukup tersedia dan terus berkurang karena diambil untuk pertumbuhan tanaman dan terangkut pada waktu panen, tercuci, menguap dan erosi. Untuk mencukupi kekurangan unsur hara $\mathrm{N}, \mathrm{P}$ dan $\mathrm{K}$ perlu dilakukan pemupukan. Pemupuk yang sesuai untuk memenuhi kebutuhan hara-hara tersebut sekaligus adalah pupuk Phonska. 


\section{Jumlah tandan buah segar}

Tabel 4. Rata-Rata Jumlah TBS pada Perlakuan Pupuk NPK Phonska

\begin{tabular}{ccccc}
\hline Pupuk NPK & \multicolumn{4}{c}{ Jumlah TBS pada bulan } \\
\cline { 2 - 5 } Phonska & Mei & Juni & Juli & Agustus \\
\hline $\mathrm{m}_{0}$ & 1,17 & $1,00^{\mathrm{b}}$ & 1,33 & 1,00 \\
$\mathrm{~m}_{1}$ & 1,17 & $1,00^{\mathrm{b}}$ & 1,50 & 1,00 \\
$\mathrm{~m}_{0}$ & 1,50 & $1,50^{\mathrm{a}}$ & 1,83 & 1,33 \\
$\mathrm{~m}_{1}$ & 1,50 & $1,33^{\mathrm{a}}$ & 1,50 & 1,17 \\
\hline
\end{tabular}

Keterangan : Angka-angka yang diikuti huruf yang sama menunjukkan tidak berbeda nyata berdasarkan uji BNT pada taraf $\alpha=5 \%$

Hasil sidik ragam menunjukan bahwa perlakuan pemberian pupuk NPK Phonska tidak berpengaruh nyata terhadap jumlah tandan buah segar kelapa sawit kecuali pada panen kedua berpengaruh sangat nyata. Hasil uji BNT 5\% menunjukkan bahwa rata-rata jumlah tandan buah segar terbanyak pada panen kedua dicapai pada perlakuan $\mathrm{m}_{2}(1,0 \mathrm{~kg} /$ pokok tanaman $)$ adalah 1,50 TBS sedangkan rata-rata jumlah tandan buah segar paling sedikit dicapai pada perlakuan $\mathrm{m}_{0}$ (Tanpa perlakuan) dan $\mathrm{m}_{1}(0,5 \mathrm{~kg} /$ pokok tanaman) adalah 1,50 TBS. Hal ini diduga karena perlakuan $\mathrm{M}_{2}$ telah mencukupi kekurangan unsur hara $\mathrm{N}, \mathrm{P}$ dan $\mathrm{K}$ untuk meningkatkan produksi tanaman kelapa sawit. Pada panen pertama, ketiga dan keempat perlakuan pemberian pupuk NPK Phonska tidak berpengaruh nyata, hal ini diduga karena perlakuan pemberian pupuk NPK Phonska sekali saja selama pengamatan sehingga pemanfaatan unsur hara $\mathrm{N}, \mathrm{P}, \mathrm{K}$ untuk meningkatkan produksi tanaman kelapa sawit terutama untuk parameter jumlah tandan buah segar hanya berpengaruh nyata pada panen kedua atau sekitar dua bulan setelah perlakuan pemberian pupuk NPK Phonska. Pada panen pertama tidak berpengaruh nyata diduga karena unsur hara $\mathrm{N}, \mathrm{P}, \mathrm{K}$ belum terserap secara optimal sehingga belum dapat dimanfaatkan secara maksimal untuk produksi tanaman kelapa sawit. Sedangkan Pada panen ketiga dan keempat perlakuan pemberian pupuk NPK Phonska tidak berpengaruh nyata diduga karena unsur hara yang tersedia tidak mencukupi kebutuhan unsur hara tanaman untuk berproduksi karena telah terangkut pada waktu panen. Hal ini sesuai dengan pendapat dengan pendapat Islami dan Utomo (1995), agar tanaman dapat tumbuh dengan baik diperlukan unsur hara dan air yang cukup dan seimbang. Kemudian diperjelas oleh Petrokimia (2005) yang menyatakan bahwa unsur hara N, P, $\mathrm{K}$ di dalam tanah tidak cukup tersedia dan terus berkurang karena diambil untuk pertumbuhan tanaman dan terangkut pada waktu panen, tercuci, menguap dan erosi. Untuk mencukupi kekurangan unsur hara $\mathrm{N}, \mathrm{P}$ dan $\mathrm{K}$ perlu dilakukan pemupukan. Kemudian ditambahkan oleh Sarief (1986), ketersedian unsur hara yang dapat diserap oleh tanaman merupakan faktor untuk mempengaruhi tingkat produksi tanaman.

\section{Pengaruh Interaksi Perlakuan Penunasan dan Pemberian Pupuk NPK Phonska}

\section{Berat tandan buah segar $(\mathrm{kg})$}

Tabel 5. Rata-Rata Jumlah Berat TBS pada Interaksi Perlakuan Penunasan dan Pupuk NPK Phonska

\begin{tabular}{ccccc}
\hline Interaksi & \multicolumn{4}{c}{ Jumlah TBS pada bulan } \\
\cline { 2 - 5 } Perlakuan & Mei & Juni & Juli & Agustus \\
\hline $\mathrm{p}_{0} \mathrm{~m}_{0}$ & $9,67^{\mathrm{d}}$ & $12,33^{\mathrm{d}}$ & $14,00^{\mathrm{d}}$ & $13,67^{\mathrm{c}}$ \\
$\mathrm{p}_{0} \mathrm{~m}_{1}$ & $10,00^{\mathrm{d}}$ & $12,33^{\mathrm{d}}$ & $14,33^{\mathrm{d}}$ & $14,00^{\mathrm{c}}$ \\
$\mathrm{p}_{0} \mathrm{~m}_{2}$ & $11,00^{\mathrm{d}}$ & $13,00^{\mathrm{d}}$ & $15,00^{\mathrm{d}}$ & $15,00^{\mathrm{c}}$ \\
$\mathrm{p}_{0} \mathrm{~m}_{3}$ & $10,00^{\mathrm{d}}$ & $13,00^{\mathrm{d}}$ & $16,00^{\mathrm{d}}$ & $16,00^{\mathrm{bc}}$ \\
$\mathrm{p}_{1} \mathrm{~m}_{0}$ & $14,00^{\mathrm{cd}}$ & $14,67^{\mathrm{cd}}$ & $24,33^{\mathrm{c}}$ & $21,00^{\mathrm{bc}}$ \\
$\mathrm{p}_{1} \mathrm{~m}_{1}$ & $18,33^{\mathrm{c}}$ & $21,67^{\mathrm{c}}$ & $41,33^{\mathrm{b}}$ & $26,00^{\mathrm{b}}$ \\
$\mathrm{p}_{1} \mathrm{~m}_{2}$ & $48,33^{\mathrm{a}}$ & $53,33^{\mathrm{a}}$ & $64,67^{\mathrm{a}}$ & $46,67^{\mathrm{a}}$ \\
$\mathrm{p}_{1} \mathrm{~m}_{3}$ & $39,67^{\mathrm{b}}$ & $38,67^{\mathrm{b}}$ & $48,33^{\mathrm{b}}$ & $36,67^{\mathrm{a}}$ \\
\hline
\end{tabular}

Keterangan : Angka-angka yang diikuti huruf yang sama menunjukkan tidak berbeda nyata berdasarkan uji BNT pada taraf $\alpha=5 \%$ 
Hasil sidik ragam menunjukan bahwa kombinasi perlakuan penunasan dan pemberian pupuk NPK Phonska berpengaruh sangat nyata terhadap berat tandan buah segar kelapa sawit pada panen pertama sampai ketiga dan berpengaruh nyata pada panen keempat. Hasil uji BNT 5\% menunjukkan rata-rata berat tandan buah segar terberat dicapai pada kombinasi perlakuan penunasan dan pemberian pupuk NPK Phonska $\mathrm{p}_{1} \mathrm{~m}_{2}\{($ dengan penunasan $)+(1,0 \mathrm{~kg} /$ pokok tanaman) $\}$ berturut - turut adalah $48,33 \mathrm{~kg}$ (panen pertama), 53,33 kg (panen kedua), 64,67 $\mathrm{kg}$ (panen ketiga) dan 46,67 kg (panen keempat) sedangkan rata-rata berat tandan buah segar teringan dicapai pada perlakuan $\mathrm{p}_{0} \mathrm{~m}_{0}\{($ tanpa penunasan $)+($ tanpa perlakuan $)\}$ berturut - turut adalah 9,67 kg (panen pertama), 12,33 kg (panen kedua), 14,00 kg (panen ketiga) dan 13,67 kg (panen keempat). Hal ini diduga karena perlakuan $\mathrm{p}_{1} \mathrm{~m}_{2}$ telah mampu memenuhi kebutuhan unsur hara tanaman dan tanaman kelapa sawit yang diberi perlakuan dengan penunasan mempunyai bidang fotosintesis yang optimal sesuai dengan kebutuhannya untuk produksi tanaman kelapa sawit. Menurut Petrokimia (2005) yang menyatakan bahwa agar tanaman dapat tumbuh dengan baik dan menghasilkan produksi yang tinggi, diperlukan unsur hara atau makanan yang cukup. Untuk hara utama yang dibutuhkan tanaman adalah Nitrogen $(\mathrm{N})$, Fosfor $(\mathrm{P})$, dan Kalium (K). Tidak dipenuhinya salah satu unsur hara tersebut akan mengakibatkan menurunnya kwalitas dan kuantitas hasil produksi pertanian. Kemudian diperjelas oleh Sunarko (2007) yang menyatakan bahwa faktor daun sangat penting hubungannya dengan pembentukan putik buah saat diferensiasi sel dan berfungsi dapur asimilat . Potensi produksi tanaman kelapa sawit hingga berumur 15 tahun terus meningkat. Karenanya, tanaman kelapa sawit harus mempunyai bidang fotosintesis yang optimal sesuai dengan kebutuhannya. Untuk mencapai tujuan itu, tunasan diatur dengan sistem songgo buah dua timbang air, sehingga tidak banyak daun yang dipotong. Oleh karena itu dengan perlakuan $\mathrm{p}_{1} \mathrm{~m}_{2}$ telah mencukupi kebutuhan unsur hara tanaman untuk melaksanakan kegiatan fotosintesis secara optimal karena tanaman mempunyai jumlah daun dengan bidang fotosintesis yang optimal sesuai dengan kebutuhannya yang ditunjukkan dengan parameter berat tandan buah segar terbaik pada perlakuan $\mathrm{p}_{1} \mathrm{~m}_{2}$. Hal ini sesuai dengan pendapat Jumin (2002), penumpukan fotosintat dapat berupa buah, biji, daun dan batang.

\section{Jumlah tandan buah segar}

Tabel 6. Rata-Rata Jumlah TBS pada Interaksi Perlakuan Penunasan dan Pupuk NPK Phonska

\begin{tabular}{ccccc}
\hline Interaksi & \multicolumn{4}{c}{ Jumlah TBS pada bulan } \\
\cline { 2 - 5 } Perlakuan & Mei & Juni & Juli & Agustus \\
\hline $\mathrm{p}_{0} \mathrm{~m}_{0}$ & 1,00 & $1,00^{\mathrm{b}}$ & 1,00 & 1,00 \\
$\mathrm{p}_{0} \mathrm{~m}_{1}$ & 1,00 & $1,00^{\mathrm{b}}$ & 1,00 & 1,00 \\
$\mathrm{p}_{0} \mathrm{~m}_{2}$ & 1,00 & $1,00^{\mathrm{b}}$ & 1,00 & 1,00 \\
$\mathrm{p}_{0} \mathrm{~m}_{3}$ & 1,00 & $1,00^{\mathrm{b}}$ & 1,00 & 1,00 \\
$\mathrm{p}_{1} \mathrm{~m}_{0}$ & 1,33 & $1,00^{\mathrm{b}}$ & 1,67 & 1,00 \\
$\mathrm{p}_{1} \mathrm{~m}_{1}$ & 1,33 & $1,00^{\mathrm{b}}$ & 2,00 & 1,00 \\
$\mathrm{p}_{1} \mathrm{~m}_{2}$ & 2,00 & $2,00^{\mathrm{a}}$ & 2,67 & 1,67 \\
$\mathrm{p}_{1} \mathrm{~m}_{3}$ & 2,00 & $1,67^{\mathrm{a}}$ & 2,00 & 1,33 \\
\hline
\end{tabular}

Keterangan : Angka-angka yang diikuti huruf yang sama menunjukkan tidak berbeda nyata berdasarkan uji BNT pada taraf $\alpha=5 \%$

Hasil sidik ragam menunjukan bahwa bahwa kombinasi perlakuan penunasan dan pemberian pupuk NPK Phonska berpengaruh sangat nyata terhadap jumlah tandan buah segar kelapa sawit pada panen kedua dan tidak berpengaruh nyata pada panen pertama, ketiga dan keempat. Hal ini diduga karena perlakuan pemberian pupuk NPK Phonska sekali saja selama pengamatan sehingga pemanfaatan unsur hara $\mathrm{N}, \mathrm{P}, \mathrm{K}$ untuk meningkatkan produksi tanaman kelapa sawit terutama untuk parameter jumlah tandan buah segar hanya berpengaruh sangat nyata pada panen kedua atau sekitar dua bulan setelah perlakuan pemberian pupuk NPK Phonska. Pada panen pertama tidak berpengaruh nyata diduga karena unsur hara $\mathrm{N}, \mathrm{P}, \mathrm{K}$ belum terserap secara optimal sehingga belum dapat dimanfaatkan secara maksimal untuk produksi tanaman kelapa sawit. Sedangkan Pada panen ketiga dan keempat perlakuan pemberian pupuk NPK Phonska tidak berpengaruh nyata diduga karena unsur hara yang tersedia tidak mencukupi kebutuhan unsur hara tanaman untuk berproduksi karena telah terangkut pada waktu panen. Hasil uji BNT 5\% menunjukkan rata-rata jumlah tandan buah segar kelapa sawit pada panen kedua terbanyak dicapai pada kombinasi perlakuan penunasan dan pemberian pupuk NPK Phonska $\mathrm{p}_{1} \mathrm{~m}_{2}\{($ dengan penunasan $)+(1,0 \mathrm{~kg} /$ pokok tanaman $)\}$ adalah 2,00 TBS (panen kedua), sedangkan rata-rata 
jumlah tandan buah segar paling sedikit dicapai pada perlakuan $\mathrm{p}_{0} \mathrm{~m}_{0}\{($ tanpa penunasan $)+($ tanpa perlakuan $)\}, \mathrm{p}_{0} \mathrm{~m}_{1}\{($ tanpa penunasan $)+(0,5 \mathrm{~kg} /$ pokok tanaman $)\}, \mathrm{p}_{0} \mathrm{~m}_{2}\{($ tanpa penunasan $)+(1,0$ $\mathrm{kg} /$ pokok tanaman $)\}, \mathrm{p}_{0} \mathrm{~m}_{3}\{($ tanpa penunasan $)+$ (1,5 kg / pokok tanaman) $\}$ adalah 1,00 TBS. Hal ini diduga karena perlakuan $\mathrm{p}_{1} \mathrm{~m}_{2}$ telah mampu memenuhi kebutuhan unsur hara tanaman dan tanaman kelapa sawit yang diberi perlakuan dengan penunasan mempunyai ruang yang cukup untuk memudahkan penyerbukan untuk pembentukan buah. Hal ini sesuai dengan Sastrosayono (2003) yang menyatakan bahwa penunasan dilakukan dengan tujuan membersihkan tanaman supaya pollen mudah

\section{KESIMPULAN}

1. Perlakuan penunasan berpengaruh sangat nyata terhadap berat TBS dan jumlah TBS. Perlakuan penunasan terbaik pada $\mathrm{P}_{1}$ (dengan penunasan). Rata-rata berat TBS pada perlakuan $\mathrm{p}_{1}$ berturut - turut adalah $30,08 \mathrm{~kg}$ (panen pertama), 32,08 $\mathrm{kg}$ (panen kedua), $44,67 \mathrm{~kg}$ (panen ketiga) dan 32,58 kg (panen keempat) sedangkan rata-rata jumlah TBS pada perlakuan $\mathrm{p}_{1}$ berturut - turut adalah 1,67 TBS (panen pertama), 1,42 TBS (panen kedua), 2,08 TBS (panen ketiga) dan 1,25 TBS (panen keempat)

2. Perlakuan pemberian pupuk NPK Phonska berpengaruh sangat nyata terhadap peningkataan produksi tanaman kelapa sawit,

\section{DAFTAR PUSTAKA}

Hardjowigeno,S. 1992. Ilmu Tanah. Medyatama Sarana Swadaya, Jakarta.

Islami T. dan Utomo, 1995. Hubungan Tanah, Air dan Tanaman, IKIP Semarang Press, Semarang.

Jumin HB, 2002. Agronomi. Raja Grafindo Persada, Jakarta.

Petrokimia, 2005. Phonska; Pupuk Majemuk NPK. P.T. Petrokimia, Gresik. membuahi putik (bunga betina). Kemudian diperjelas oleh Petrokimia (2005) yang menyatakan bahwa manfaat pupuk NPK Phonska adalah memacu pembentukan bunga, mempercepat pemasakan biji sehingga panen lebih cepat. Oleh karena itu dengan perlakuan $\mathrm{p}_{1} \mathrm{~m}_{2}$ telah mencukupi kebutuhan unsur hara tanaman untuk kegiatan fotosintesis secara optimal serta tanaman mempunyai jumlah daun yang optimal sesuai dengan kebutuhannya sehingga memudahkan penyerbukan untuk pembentukan buah yang ditunjukkan dengan parameter jumlah tandan buah segar terbaik pada perlakuan $\mathrm{p}_{1} \mathrm{~m}_{2}$.

dimana perlakuan terbaik pada perlakuan $\mathrm{M}_{2}$ $(1,0 \mathrm{~kg} /$ pokok tanaman). Rata-rata berat TBS pada perlakuan $\mathrm{m}_{2}$ berturut - turut adalah $29,67 \mathrm{~kg}$ (panen pertama), 33,17 kg (panen kedua), 39,83 $\mathrm{kg}$ (panen ketiga) dan $30,83 \mathrm{~kg}$ (panen keempat)

3. Terdapat interaksi antara perlakuan penunasan dengan pemberian pupuk NPK Phonska terhadap peningkataan produksi tanaman kelapa sawit, dimana kombinasi perlakuan terbaik pada $\mathrm{p}_{1} \mathrm{~m}_{2}\{($ dengan penunasan $)+(1,0 \mathrm{~kg} /$ pokok tanaman $)\}$. Rata-rata berat TBS pada perlakuan $\mathrm{p}_{1} \mathrm{~m}_{2}$ berturut - turut adalah $48,33 \mathrm{~kg}$ (panen pertama), 53,33 kg (panen kedua), 64,67 kg (panen ketiga) dan 46,67 $\mathrm{kg}$ (panen keempat).

Sarief ES, 1986. Kesuburan dan Pemupukan Tanah Pertanian, Pustaka Buana, Bandung.

Sastrosayono, 2003. Budidaya kelapa Sawit, Agromedia Pustaka, Jakarta.

Sunarko,2007. Petunjuk Praktis Budidaya dan Pengolahan Kelapa Sawit, Agramedia Pustaka, Jakarta. 